\title{
Preparation and Morphologies of Shell Cross-Linked Micelles Based on Commercial Poly(styrene-block-ethylene-co-butene-block-styrene)
}

\author{
Tianlong LI, ${ }^{*, * *}$ Fanglin Ning, ${ }^{*, * *}$ Jingwei XIE, ${ }^{*, * *}$ Daoyong ChEN, ${ }^{*, * *}$ and Ming JIANG ${ }^{*, * *, \dagger}$ \\ *Department of Macromolecular Science, Fudan University, Shanghai 200433, People's Republic of China \\ ${ }^{* *}$ The Key Laboratory of Molecular Engineering of Polymers, Ministry of Education, Shanghai 200433, People's Republic of China
}

(Received January 15, 2002; Accepted April 26, 2002)

\begin{abstract}
Chloromethyl groups were introduced into the polystyrene (PS) blocks of hydrogenated poly(styreneblock-butadiene-block-styrene) (SEBS) via Friedel-Crafts reaction. The product $\left(\mathrm{SEBS}-\mathrm{CH}_{2} \mathrm{Cl}\right)$ formed spherical micelles with PS corona and hydrogenated PB core in THF/ethanol $(10 / 9, \mathrm{v} / \mathrm{v})$. Then, the polystyrene corona carrying $\mathrm{CH}_{2} \mathrm{Cl}$ groups was cross-linked by amination with 1,6-hexanediamine as a cross linker. The shell cross-linked micelles showed spherical core-shell structure and were stable in solution, which was verified by DLS in solution and by TEM in the solid state.

KEY WORDS poly(styrene-block-butadiene-block-styrene) (SEBS) / Shell Cross-Linked Micelle

/ Chloromethylation / Amination/
\end{abstract}

The creation of novel polymeric nanomaterials with the appropriate morphologies and functions for potential applications has become an intensely studied field of nanotechnology. Recently Wooley and coworkers have reported the synthesis of shell crosslinked "knedel" (SCK) micelles. ${ }^{1-5}$ SCK's belong to a new class of nanomaterials which resemble polymer micelles in their core-shell morphology as well as dendrimers and arborescent polymers in being covalently bound and stable structures. ${ }^{2}$ Various applications in areas as diverse as solubilization, catalysis, fillers, coatings, and delivery have been proposed for these fascinating new materials. ${ }^{1}$

The generally applicable synthetic approach to the preparation of SCK nanoparticles involves micellization of amphiphilic block copolymers in aqueous solution, followed by cross-linking the chain segments composing the hydrophilic shell domain via addition of multifunctional cross-linking agents or radical addition polymerization of side groups. ${ }^{6}$ Besides, entirely hydrophobic, ${ }^{7}$ hydrophilic, ${ }^{8}$ and zwitterionic ${ }^{9}$ shell cross-linked micelles were reported as well, as a significant extension of the study of SCK's. Some procedures such as designing temperature-variable core hydrophilicity ${ }^{8}$ and performing the cross-linking at an intermediate layer within the polymer micelles ${ }^{10}$ are also developped to overcome limitations of possible applications and general approaches.

Currently, the precursors for SCK's are mainly the block copolymers with a cross-linkable block. All the copolymers were prepared in laboratories by living polymerization, particularly, sequential anionic polymerization. ${ }^{1-10}$ However, the preparation of such re-

${ }^{\dagger}$ To whom correspordence should be addressed. quired block copolymers is usually costly and timeconsuming. On the other hand, although the commercial block copolymers are relatively cheap and immediately available they are hardly used as the precursors for lack of cross-linkable functional groups. As reported previously by us, ${ }^{11,12}$ hydrogenated poly(styreneblock-butadiene-block-styrene) (SEBS) being a thermoelastomer with excellent properties, can be modified by controllably introducing functional groups without changing the original well defined structure. Here we report the preparation of shell cross-linked micelles starting from SEBS in mixed solvents by successive chloromethylation and amination. This achievement not only contributed a new member to the SCK family but also linked up the traditional commercial block copolymer product to the novel nanomaterial SCK.

\section{EXPERIMENTAL}

\section{Materials}

Monodisperse SEBS (G1652, Shell Co) with $M_{\mathrm{n}}=$ $52500, M_{\mathrm{w}} / M_{\mathrm{n}} \leq 1.06$, and $28.6 \mathrm{wt} \%$ styrene units was used as the starting material. 1,6-Hexanediamine was used as the cross linker. $\mathrm{SnCl}_{4}$, trioxane, and chlorotrimethylsilane were purified by routine methods.

\section{Chloromethylation of SEBS and Characterization}

To avoid cross-linking and degradation of SEBS in the process of chloromethylation, saturation of the residue double bonds in the EB block was performed via successive bromination and hydrogenolysis according to the procedures reported previously. ${ }^{11}$ The chloromethylation procedure was as follows. ${ }^{13}$ Typi- 
cally, trioxane $(18 \mathrm{~g}, 0.2 \mathrm{~mol})$ and chlorotrimethylsilane $(76 \mathrm{~mL}, 0.6 \mathrm{~mol})$ were dissolved in chloroform $(300 \mathrm{~mL})$. The saturated SEBS $(5 \mathrm{~g})$ was added to the above solution and was allowed to be dissolved fully under stirring. After the reaction mixture was cooled to $0^{\circ} \mathrm{C}, 10 \mathrm{~mL}(0.05 \mathrm{~mol})$ of $\mathrm{SnCl}_{4}$ was added. The mixture was stirred at $0^{\circ} \mathrm{C}$ for $30 \mathrm{~min}$ and then at room temperature for another $8 \mathrm{~h}$. The reaction was quenched by adding $50 / 50(\mathrm{v} / \mathrm{v})$ methanol/water to the reaction mixture. The product was purified by repeated reprecipitation in THF/water, and then was dried under vacuum. The final sample denoted as SEBS- $\mathrm{CH}_{2} \mathrm{Cl}$ was characterized by GPC, NMR, and FT-IR.

\section{Micellization and Shell Cross-Linking of SEBS-CH${ }_{2} \mathrm{Cl}$ to Form SCK's}

Typically, $10 \mathrm{mg}$ of SEBS- $\mathrm{CH}_{2} \mathrm{Cl}$ with $43.2 \mathrm{~mol} \%$ of $-\mathrm{CH}_{2} \mathrm{Cl}$ content based on styrene units was first dissolved in $10 \mathrm{~mL}$ of distilled THF $\left(1 \mathrm{mg} \mathrm{mL}^{-1}\right)$. Under vigorous stirring, ethanol $(9 \mathrm{~mL})$ was added dropwise $\left(0.1 \mathrm{~mL} \mathrm{~min}^{-1}\right)$ to induce micellization. The micellar solution was equilibrated at room temperature for $24 \mathrm{~h}$ before micelle cross-linking as follows. To $100 \mathrm{~mL}$ of SEBS- $\mathrm{CH}_{2} \mathrm{Cl}$ micellar solution $\left(0.5 \mathrm{mg} \mathrm{mL}{ }^{-1}, 5.76 \times 10^{-2} \mathrm{mmol}-\mathrm{CH}_{2} \mathrm{Cl}\right)$ was added diamino linker $\left(5.76 \times 10^{-2} \mathrm{mmol}-\mathrm{NH}_{2}\right)$. The reaction mixture was stirred at $35^{\circ} \mathrm{C}$ for $7-10$ days. Samples $(1 \mathrm{~mL}$ each) were taken at different reaction times, which were diluted with THF and used for DLS and TEM measurements. The rest of the reaction mixture was purified by precipitation in ethanol.

\section{Dynamic Light Scattering and Transmission Electron Microscopic Studies}

Dynamic light scattering (DLS) measurements were performed in order to get the z-average distribution of apparent hydrodynamic diameter, $D_{\mathrm{h}}$, of the aggregates. A commercial laser light scattering (LLS) spectrometer (Malvern Autosizer 4700) equipped with a multi- $\tau$ digital time correlation (Malvern PCS7132), PCS stepper motor controller and a solid-state laser (ILT 5500QSL, output power $=100 \mathrm{mw}$ at $\lambda_{0}=$ $514.5 \mathrm{~nm}$ ) was used. In DLS, the line-width distribution $G(\Gamma)$ can be calculated from the Laplace inversion of intensity-intensity time correlation function $G^{(2)}(q, t)$. In this study, the correlation functions were analyzed by the CONTIN program which can give access to the distribution of the correlation times in the experimental time. The correlation functions and then the z-average distributions of $D_{\mathrm{h}}$ were calculated. All the DLS measurements were done at $25^{\circ} \mathrm{C}$ at a scattering angles of $90^{\circ}$ and a concentration of $0.1-0.5 \mathrm{mg} \mathrm{mL}^{-1}$. All the sample solution was filtered using a $0.22 \mu \mathrm{m}$ Millipore filter.

Transmission electron microscope (TEM) observation was carried out on a Philips EM400 microscope at an accelerating voltage of $80 \mathrm{kV}$. The samples were prepared by immersing a copper grid, which was coated with a thin film of Formvar and carbon successively, into the solution of micelles or SCK's. The copper grids were immediately transferred into a metal cell and subsequently frozen by liquid nitrogen and then freezedried under vacuum for $5 \mathrm{~h}$.

\section{RESULTS AND DISCUSSION}

As shown in Scheme 1, there are three main steps for the preparation of SCK's : (1) chloromethylation of SEBS, introducing reactive functionalities into the PS block to form SEBS- $\mathrm{CH}_{2} \mathrm{Cl}$; (2) micellization of SEBS- $\mathrm{CH}_{2} \mathrm{Cl}$ in a mixed solvent at a concentration low enough to prevent intermicellar reactions; and (3) cross-linking throughout the peripheral layer by reactions of the side groups along the PS shell.

SEBS- $\mathrm{CH}_{2} \mathrm{Cl}$ with different extent of chloromethylation was prepared by Friedel-Crafts reaction with stannic chloride $\left(\mathrm{SnCl}_{4}\right)$ as catalyst in chloroform solution in the presence of trioxane and chlorotrimethylsilane. The samples were characterized by FT-IR, ${ }^{1} \mathrm{H}$ NMR and SEC. The FT-IR spectra of SEBS- $\mathrm{CH}_{2} \mathrm{Cl}$ exhibit the characteristic bands of $\mathrm{C}-\mathrm{Cl}$ stretch $(v=$ $1265 \mathrm{~cm}^{-1}$ ) and the ${ }^{1} \mathrm{H}$ NMR spectrum in Figure 1 displays the absorption at $\delta=4.49 \mathrm{ppm}$, corresponding to the protons in $-\mathrm{CH}_{2} \mathrm{Cl}$. The extent of chloromethylation was determined from the ratio of the peak area of $-\mathrm{CH}_{2} \mathrm{Cl}$ to that of the benzene ring from the ${ }^{1} \mathrm{H}$ NMR spectra. The SEC spectra in THF reveal that all the SEBS- $\mathrm{CH}_{2} \mathrm{Cl}$ samples with the degree of chloromethylation ranging from $9 \mathrm{~mol} \%$ to $73.8 \mathrm{~mol} \%$ possess a

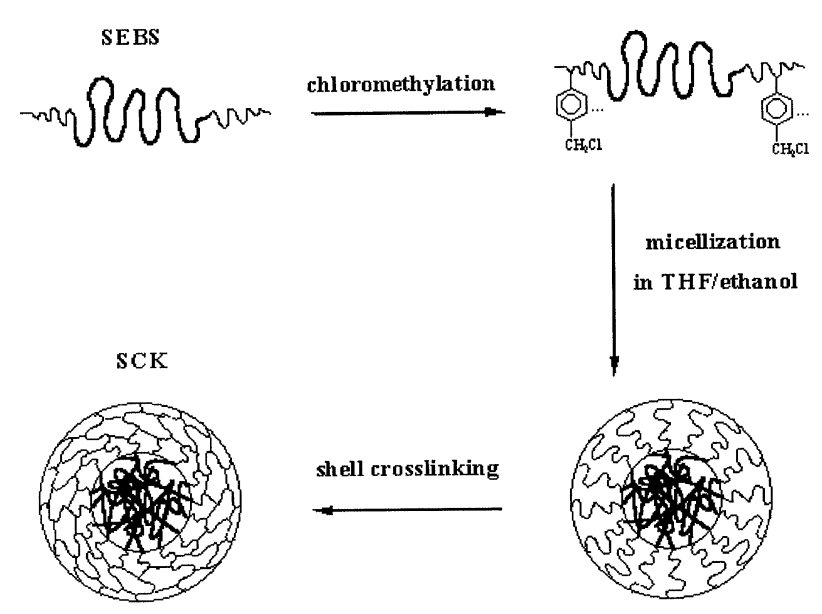

Scheme 1. A illustration of the three-step synthesis to prepare SCK's: (1) chloromethylation of SEBS; (2) self-assembly of SEBS$\mathrm{CH}_{2} \mathrm{Cl}$ into micelles; (3) cross-linking of the shell layer by amination. 


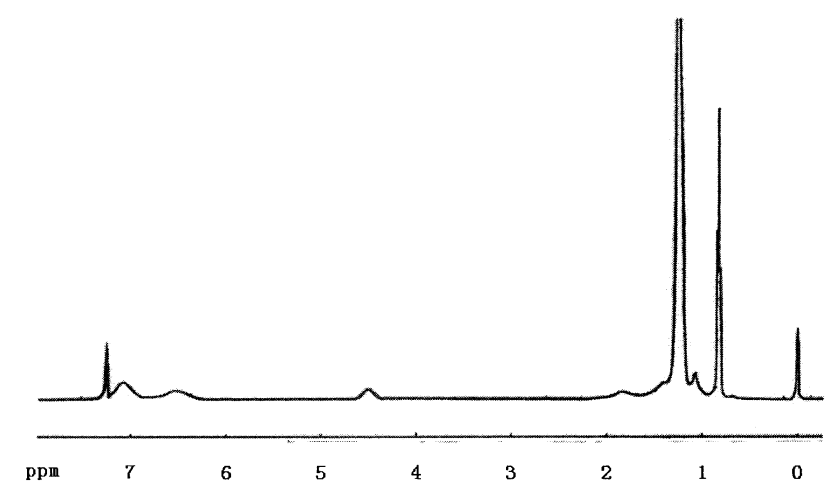

Figure 1. ${ }^{1} \mathrm{H}$ NMR spectrum of $\mathrm{SEBS}-\mathrm{CH}_{2} \mathrm{Cl}$ (functionality $43.2 \mathrm{~mol} \%)$.

low polydispersity, i.e., $M_{\mathrm{w}} / M_{\mathrm{n}}$ ranges from 1.09 to 1.25. Compared to the starting material SEBS with $M_{\mathrm{w}} / M_{\mathrm{n}} \leq 1.06$, it is clear that chloromethylation only slightly alters the monodispersity. The combination of SEC, FT-IR and ${ }^{1} \mathrm{H}$ NMR demonstrated that the chloromethylation can be performed to obtain SEBS$\mathrm{CH}_{2} \mathrm{Cl}$ with $-\mathrm{CH}_{2} \mathrm{Cl}$ content as high as about $70 \mathrm{~mol} \%$ based on polystyrene units without cross-linking and degradation. To demonstrate the effect of the extent of chloromethylation upon preparation of SCK's, a series of SEBS- $\mathrm{CH}_{2} \mathrm{Cl}$ with a broad range of the degree of chloromethylation from $9 \mathrm{~mol} \%$ to $73.8 \mathrm{~mol} \%$ was empolyed. By cross-linking the micelles with different chloromethyl content, it was found that the resultant SCK's with the functionality over $40 \mathrm{~mol} \%$ showed a desired stability.

Initially, 4,4'-bipyridyl was selected as the cross linker because of its good ability to perform amination. However, it failed to produce the cross-linked shell as dissociation of the micelles occurred when the solvent was switched to THF-rich medium. The failure is probably due to that the cross linker is too short and too rigid for intermolecular cross-linking. Therefore, a relatively long and flexible cross-linker 1,6-hexanediamine was then used and proved to be successful.

The success of the preparation significantly depends on reaction temperature. The reaction carried out at above $40^{\circ} \mathrm{C}$ led to the appearance of macroscopic gel, while that below $30^{\circ} \mathrm{C}$ was too slow to form stable SCK in a reasonable period. The former result can be attributed to the decreasing stability of the entirely hydrophobic micelle in organic solvent with increasing temperature, ${ }^{14}$ while the latter result can be related to the very low rate of amination reaction between $-\mathrm{NH}_{2}$ and $-\mathrm{CH}_{2} \mathrm{Cl}$. The experiments proved that the reaction temperature around $35^{\circ} \mathrm{C}$ was suitable for producing the stable SCK.

The addition of ethanol to a THF solution of SEBS$\mathrm{CH}_{2} \mathrm{Cl}$ led to selective aggregation of the butadiene blocks, which were stabilized in the solution by the sol-

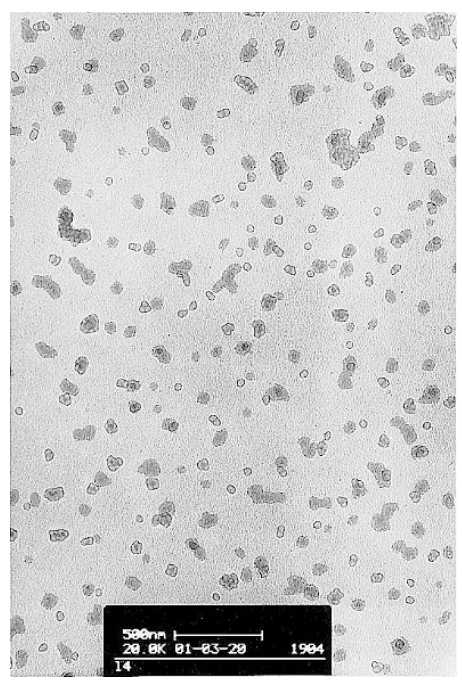

Figure 2. TEM image of micelles based on $\mathrm{SEBS}-\mathrm{CH}_{2} \mathrm{Cl}$ (functionality $43.2 \mathrm{~mol} \%$ ) sprayed from THF/ethanol (10/9, v/v).

vated chloromethylated polystyrene blocks. The formation of SEBS- $\mathrm{CH}_{2} \mathrm{Cl}$ micelles in THF/ethanol was judged from the bluish tinge of the solution. Figure 2 is a TEM image of the micelles before amination reaction. The micelles seem spherical with a dark PS shell and a gray EB core. The diameter of these micelles is approximately $40 \mathrm{~nm}$. Micelle formation was also confirmed by our dynamic light scattering experiments. The hydrodynamic diameter $D_{\mathrm{h}}$ of the micelles in THF/ethanol $(10 / 9, \mathrm{v} / \mathrm{v})$ from DLS measurements was determined to be $42 \mathrm{~nm}$, which coincides with the TEM results. The size distribution of the micelles in THF/ethanol $(10 / 9, v / v)$ is shown in Figure 3a in which a polydispersity index of 0.17 was found by DLS.

After shell cross-linking of the micelles by amination reaction, the reaction solution became slightly turbid. A similar phenomenon which indicated the formation of some large micelles and micellar aggregates was reported by Wooley. ${ }^{3}$ The hydrodynamic diameter $D_{\mathrm{h}}$ of the SCK micelles in THF/ethanol $(10 / 9, \mathrm{v} / \mathrm{v})$ measured by DLS after filtration was found to be $43 \mathrm{~nm}$. The difference in the hydrodynamic diameter between the SCK and the parent micelle is negligible, which is different from those previously reported. ${ }^{1-10}$ For those SCK's the size was smaller than the corresponding parent micelles because of the decreasing solubility of the shell component with shell cross-linking reaction. ${ }^{15}$ However, in the present case the amination produces positively charged units in the shell, which increase swelling of the shell in THF/ethanol. In Figure 3b, the size distribution of the SCK micelles becomes narrow as indicated by the polydispersity index being 0.08 by DLS. This was also confirmed by our TEM observations (Figure 4). The size of the scattered individual SCK generally coincides with the DLS results. Some 


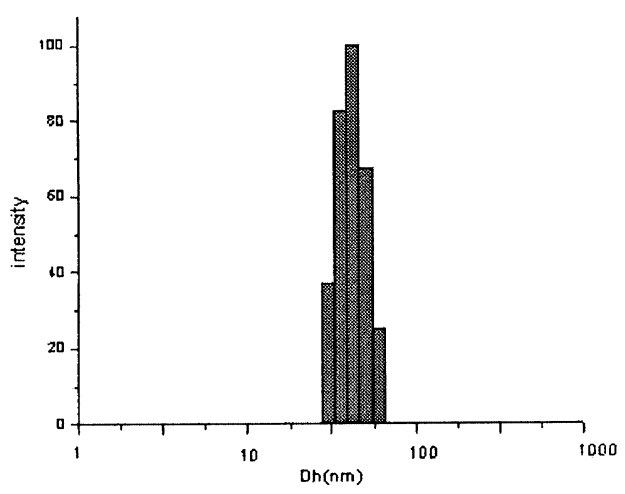

(a)

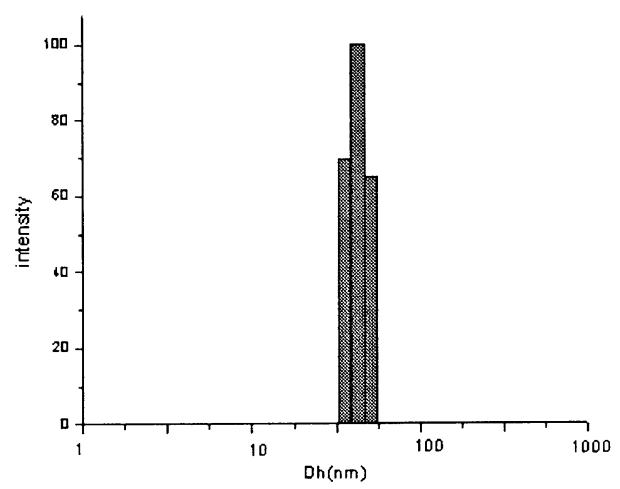

(b)

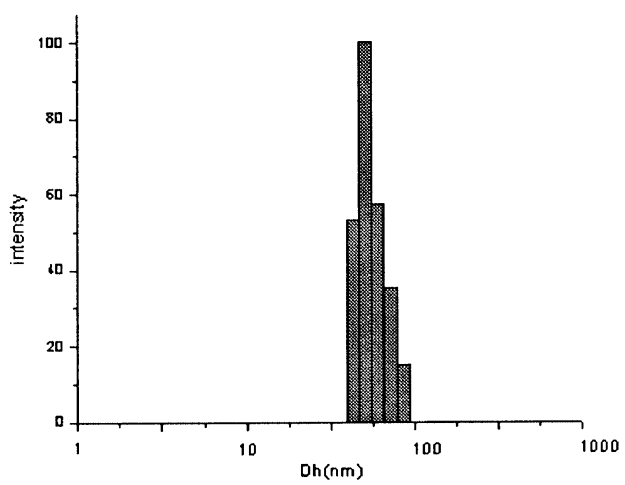

(c)

Figure 3. The size distribution measured by DLS of (a) micelles based on SEBS- $\mathrm{CH}_{2} \mathrm{Cl}$ (functionality $43.2 \mathrm{~mol} \%$ ) in THF/ethanol (10/9, v/v) and (b) SCK based on the SEBS- $\mathrm{CH}_{2} \mathrm{Cl}$ in THF/ethanol $(10 / 9, \mathrm{v} / \mathrm{v})$, (c) SCK based on the SEBS- $\mathrm{CH}_{2} \mathrm{Cl}$ in THF/ethanol $(10 / 1, \mathrm{v} / \mathrm{v}) .\left(\mathrm{C}=0.1-0.5 \mathrm{mg} \mathrm{mL}^{-1}\right)$.

aggregates composed of a few SCK micelles were observed as well.

The shell crosslinking was verified further as follows. After exposure to 1,6-hexanediamine for several days at $35^{\circ} \mathrm{C}$, the SCK's micellar solution was diluted with four times volume of THF. As is shown by Figure 3c, DLS studies indicated the continued presence of the micelles in such THF-rich solvent mixture which was able to dissolve the linear functionallized SEBS chains. The hydrodynamic diameter $D_{\mathrm{h}}$ of the SCK micelles in THF/ethanol $(10 / 1, \mathrm{v} / \mathrm{v})$ was determined to be $56 \mathrm{~nm}$. The increase in SCK micelles diameter after dilution

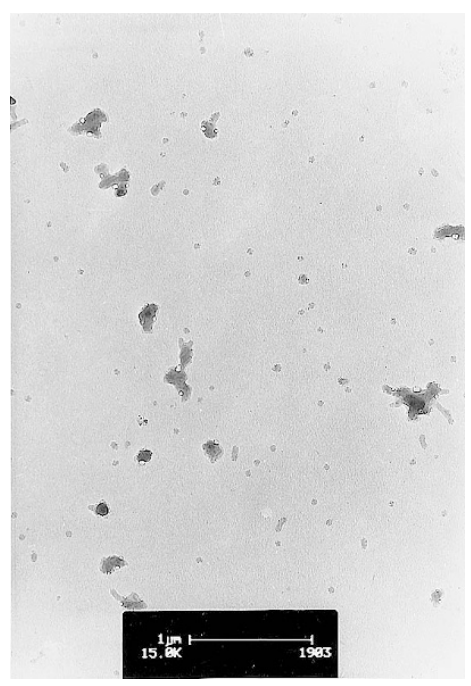

Figure 4. TEM image of $\mathrm{SCK}$ based on $\mathrm{SEBS}-\mathrm{CH}_{2} \mathrm{Cl}$ (functionality $43.2 \mathrm{~mol} \%$ ) sprayed from THF/ethanol (10/9, v/v).

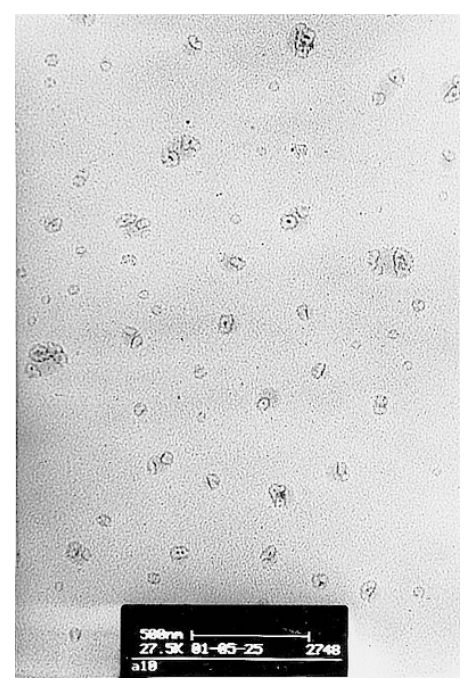

Figure 5. TEM image of SCK based on SEBS- $\mathrm{CH}_{2} \mathrm{Cl}$ (functionality $43.2 \mathrm{~mol} \%$ ) after dilution sprayed from THF/ethanol $(10 / 1, v / v)$.

with THF is probably due to some degree of swelling of the EB core by the THF-rich solvent. Meanwhile, it was observed that the size distribution of the SCK micelles in THF/ethanol $(10 / 1, \mathrm{v} / \mathrm{v})$ became broader as the polydispersity index increased to 0.26 . The success in SCK preparation was also confirmed by our TEM experiments. Figure 5 is a TEM image of SCK's after dilution with THF. The SCK after dilution still retained their spherical shape and the distinct core-shell structure, which demonstrates the stability induced by the shell cross-linking. The average diameter of SCK after THF dilution in the TEM image was approximately $50 \mathrm{~nm}$, which coincided with that of DLS measurements (Figure 3c). Finally, it is worth noting that in a control experiment for a micelle solution treated with the same procedure but without the cross linker, dissociation of the micelles into the individual triblock 
copolymer chains took place.

\section{CONCLUSION}

Although SCK's have been produced extensively from the entirely hydrophobic or hydrophilic as well as amphiphilic block copolymers that were specially designed and synthesized in laboratories, little work has been done to prepare SCK based on the common and commercially available block copolymers. The starting material for this work is a commercial product of SEBS. SEBS- $\mathrm{CH}_{2} \mathrm{Cl}$ spherical micelles with EB cores were formed in THF/ethanol. The shell cross-linking of the micelles by amination using 1,6-hexanediamine as a linker led to the formation of the SCK. The evidence for cross-linking is clearly seen in the enhanced stabilities of the SCK's in comparison to the micelle precursor. The work presents the way to make use of the commercial block copolymer by chemical modification to prepare the SCK. The SCK based on SEBS- $\mathrm{CH}_{2} \mathrm{Cl}$ is expected to serve as a nanoscale container with shape adaptability due to the fluid core behavior. As far as this is concerned, it has the great potential for kinds of applications.

Acknowledgment. This work was supported by the Grand Project of National natural Science Foundation of China (NNSFC 29992590), which is gratefully acknowledged.

\section{REFERENCES}

1. K. B. Thurmond, T. Kowalewski, and K. L. Wooley, J. Am. Chem. Soc., 118, 7239 (1996).

2. H. Y. Huang, T. Kowalewski, E. E. Remsen, R. Gertzmann, and K. L.Wooley, J. Am. Chem. Soc., 119, 11653 (1997).

3. a) K. B. Thurmond, T. Kowalewski, and K. L. Wooley, J. Am. Chem. Soc., 119, 6656 (1997).

b) K. L. Wooley, Chem.-Eur. J., 3, 1397 (1997).

4. H. Y. Huang, E. E. Remsen, and K. L. Wooley, Chem. Commun., 1415 (1998).

5. H. Y. Huang, E. E. Remsen, T. Kowalewski, and K. L. Wooley, J. Am. Chem. Soc., 121, 3805 (1999).

6. K. L. Wooley, J. Polym. Sci., Part A: Polym. Chem., 38, 1397 (2000).

7. J. Ding and G. Liu, Macromolecules, 31, 6554 (1998).

8. V. Bütün, N. C. Billingham, and S. P. Armes, J. Am. Chem. Soc., 120, 12135 (1998).

9. V. Bütün, A. B. Lowe, N. C. Billingham, and S. P. Armes, J. Am. Chem. Soc., 121, 4288 (1999).

10. V. Bütün, X. S. Wang, M. V. de Paz Báňez, K. L. Robinson, N. C. Billingham, and S. P. Armes, Macromolecules, 33, 1 (2000).

11. L. Liu and M. Jiang, Macromolecules, 28, 8702 (1995).

12. C. Shen, Z. Yan, and J. W. Xie, Chemical Journal of Chinese Universities, 20, 827 (1999).

13. S. Itsuno, K. Uchikoshi, and K. Ito, J. Am. Chem. Soc., 112, 8187 (1990).

14. Z. Tuzar and P. Kratochvil, Surface and Colloid Science, 15, 1 (1993).

15. E. E. Remsen, K. B. Thurmond, and K. L. Wooley, Macromolecules, 32, 3685 (1999). 